\title{
Selective Activation of the Extended Ventrolateral Preoptic Nucleus during Rapid Eye Movement Sleep
}

\author{
Jun Lu, ${ }^{1}$ Alvhild A. Bjorkum,, ${ }^{1,2}$ Man Xu, ${ }^{1}$ Stephanie E. Gaus, ${ }^{1}$ Priyattam J. Shiromani, ${ }^{3}$ and Clifford B. Saper ${ }^{1}$ \\ ${ }^{1}$ Department of Neurology, Beth Israel Deaconess Medical Center, Boston, Massachusetts 02215, ${ }^{2}$ Department of \\ Physiology, University of Bergen, Bergen N-5009, Norway, and ${ }^{3}$ Department of Neurology, Veterans Affairs Medical \\ Center, West Roxbury Harvard Medical School, Boston, Massachusetts 02132
}

We found previously that damage to a cluster of sleep-active neurons (Fos-positive during sleep) in the ventrolateral preoptic nucleus (VLPO) decreases non-rapid eye movement (NREM) sleep in rats, whereas injury to the sleep-active cells extending dorsally and medially from the VLPO cluster (the extended VLPO) diminishes REM sleep. These results led us to examine whether neurons in the extended VLPO are activated during REM sleep and the connectivity of these neurons with pontine sites implicated in producing REM sleep: the laterodorsal tegmental nucleus (LDT), dorsal raphe nucleus (DRN), and locus ceruleus (LC). After periods of dark exposure that triggered enrichment of REM sleep, the number of Fos-positive cells in the extended VLPO was highly correlated with REM but not NREM sleep. In contrast, the number of Fos-positive cells in the VLPO cluster was correlated with NREM but not REM sleep.
Sixty percent of sleep-active cells in the extended VLPO and $90 \%$ of sleep-active cells in the VLPO cluster in dark-treated animals contained galanin mRNA. Retrograde tracing from the LDT, DRN, and LC demonstrated more labeled cells in the extended VLPO than the VLPO cluster, and $50 \%$ of these in the extended VLPO were sleep-active. Anterograde tracing showed that projections from the extended VLPO and VLPO cluster targeted the cell bodies and dendrites of DRN serotoninergic neurons and LC noradrenergic neurons but were not apposed to cholinergic neurons in the LDT. The connections and physiological activity of the extended VLPO suggest a specialized role in the regulation of REM sleep.

Key words: laterodorsal tegmental nucleus; dorsal raphe nucleus; locus ceruleus; galanin; GABA; c-Fos
Recent studies show that the ventrolateral preoptic nucleus (VLPO) contains a cluster of sleep-active neurons (Sherin et al., 1996, 1998; Szymusiak et al., 1998). These sleep-active cells contain galanin and GABA (Sherin et al., 1998; Gaus et al., 2002) and project to many components of the arousal system including the histaminergic tuberomammillary nucleus (TMN), the serotoninergic dorsal raphe nucleus (DRN), and the noradrenergic locus ceruleus (LC) (Sherin et al., 1998; Steininger et al., 2001), suggesting that they may inhibit the ascending monoaminergic arousal system during sleep. After preoptic lesions, loss of neurons in the VLPO cluster correlates closely with the loss of non-rapid eye movement (NREM) sleep (Lu et al., 2000). Although REM sleep is also diminished after lesions of the VLPO region, this is not correlated with the loss of cells in the VLPO cluster, suggesting that cells nearby but outside the VLPO cluster regulate REM sleep. Numerous galaninergic cells are located dorsally and medially to the VLPO cluster (the extended VLPO), and many of them are sleep-active (Fos-positive) during sleep and are galaninergic (Gaus et al., 2002). We found that loss of sleep-active cells in the extended VLPO is correlated with a decrease in REM sleep but not NREM sleep (Lu et al., 2000).

This hypothetical role of the extended VLPO cells in REM

Received Aug. 20, 2001; revised March 12, 2002; accepted March 13, 2002.

This work was supported by United States Public Health Service Grants NS3397, HL60292, AG47755, and MH12058. We thank Quan Ha, Alex Adler, and Minh Ha for technical assistance.

Correspondence should be addressed to Dr. Clifford B. Saper, Department of Neurology, Beth Israel Deaconess Medical Center, 330 Brookline Avenue, Boston, MA 02215. E-mail: csaper@caregroup.harvard.edu.

Copyright (C) 2002 Society for Neuroscience $0270-6474 / 02 / 224568-09 \$ 15.00 / 0$ sleep control is consistent with the observations that some cells in the VLPO region fire faster during REM sleep compared with during NREM sleep or wakefulness (Koyama and Hayaishi, 1994; Osaka and Matsumura, 1994; Szymusiak et al., 1998). However, these single-unit recording studies could not determine whether the REM-active neurons were galaninergic. In addition, very little is known about the projections of the extended VLPO neurons compared with the VLPO cluster.

To address these questions, we developed a model for identifying anatomically the REM active neurons in the VLPO area. Previous studies had found that exposing rats to darkness during the daily light cycle when they are usually asleep triggers REM sleep (Alfoldi et al., 1991; Benca et al., 1991, 1998; Miller et al., 1998). We therefore correlated the number of sleep-active cells in the extended VLPO with REM sleep during dark exposure. We also determined by the combination of anterograde and retrograde tracing with immunocytochemistry and in situ hybridization whether the sleep-active cells in the extended VLPO during periods of enhanced REM sleep contain galanin and project to pontine sites believed to control production of REM sleep [i.e., the laterodorsal tegmental nucleus (LDT), DRN, and LC].

\section{MATERIALS AND METHODS}

\section{Animals}

Pathogen-free adult male Sprague Dawley rats (275-300 gm; $n=82)$ purchased from Harlan Sprague Dawley (Indianapolis, IN) were used. The rats were individually housed and had access to food and water $a d$ libitum. All animals were housed under controlled conditions (12 hr of light starting at 7:00 A.M.; 200 lux) in an isolated ventilated chamber 
maintained at $20-22^{\circ} \mathrm{C}$. All protocols were approved by the Institutional Animal Care and Use Committees of Beth Israel Deaconess Medical Center and Harvard Medical School.

\section{Physiology}

Implantation for EEG/EMG. After animals were anesthetized with chloral hydrate, the skull was exposed. Four screw electrodes were implanted into the skull, in the frontal (two electrodes) and parietal (two electrodes) bones of each side, and two flexible wire electrodes were placed in the nuchal muscles. The incisions were closed by wound clips. The electrodes were soldered to sockets that were connected via flexible recording cables and a commutator to a Grass polygraph (Grass Instruments, West Warwick, RI) and a computer.

Dark treatment and EEG recording. After 1 week on a $12 \mathrm{hr}$ light/dark schedule (lights on at 7:00 A.M.), including $2 \mathrm{~d}$ of adaptation to the EEG/EMG cables, animals were exposed to extended darkness or normal light from 7:00 A.M. to 10:00 A.M. EEG/EMG was continuously recorded during this period. After the dark or light exposure, animals were killed by vascular perfusion (see below).

Sleep analyses. The EEG/EMG signals were amplified by a polygraph (Grass Instruments) and digitized by an Apple Macintosh $(\mathrm{Cu}-$ pertino, CA) power computer running Icelus (G Systems Inc., Plano, TX). Wake-sleep states were manually scored in $12 \mathrm{sec}$ epochs on the digitized EEG/EMG. Wakefulness was identified by the presence of a desynchronized EEG and phasic EMG activity. NREM sleep consisted of a high-amplitude slow-wave EEG together with a low-EMG tone relative to waking. REM sleep was identified by the presence of regular theta activity coupled with low-EMG tone relative to NREM sleep. The amount of time spent in a wake state, NREM sleep, and REM sleep was determined for each hour.

\section{Histology and tracing}

Tracer injections. Under chloral hydrate anesthesia (7\% in saline; 350 $\mathrm{mg} / \mathrm{kg}$ ), a fine glass pipette containing a $2.5 \%$ solution of the anterograde tracer Phaseolus vulgaris leucoagglutinin (PHA-L) in saline was lowered into the extended VLPO and VLPO cluster stereotaxically [anteroposterior (AP), $-0.6 \mathrm{~mm}$; dorsoventral (DV), $-8.5 \mathrm{~mm}$; mediolateral (ML), $-1.0 \mathrm{~mm}$; with the bitebar at $-3.3 \mathrm{~mm}$ (Paxinos and Watson, 1986)]. PHA-L was injected by iontophoresis with a current of $5 \mu \mathrm{A}$ for $15 \mathrm{~min}$ (7 sec on and $7 \mathrm{sec}$ off) to give a discrete injection site $(\sim 200-300 \mu \mathrm{m}$ in diameter). After 2 additional min, the pipette was slowly withdrawn. Cholera toxin subunit B (CTB; List Biological, Campbell, CA) was injected before implantation for EEG/EMG using an air-pressure delivery system to inject $6 \mathrm{nl}$ of CTB solution (1\% in saline). CTB targets included the central DRN (AP, $-7.80 \mathrm{~mm}$; ML, $0 \mathrm{~mm}$; DV, $-5.6 \mathrm{~mm}$ ), the lateral wing of the DRN (AP, $-7.80 \mathrm{~mm}$; ML, $0.4 \mathrm{~mm}$; DV, $5.6 \mathrm{~mm}$ ), the LDT (AP, $-8.0 \mathrm{~mm}$; ML, $0.8 \mathrm{~mm}$; DV, $5.8 \mathrm{~mm}$ ), and the LC (AP, $-9.30 \mathrm{~mm}$; ML, $1.0 \mathrm{~mm}$; DV, $6.0 \mathrm{~mm}$ ). Incisions were closed with wound clips and animals survived for $7 \mathrm{~d}$.

Perfusion and histology. Animals were deeply anesthetized by chloral hydrate $(350 \mathrm{mg} / \mathrm{kg})$ and then perfused through the heart with $50 \mathrm{ml}$ of saline followed by $500 \mathrm{ml}$ of $10 \%$ formalin. The brains were removed and postfixed in $10 \%$ formalin for $4 \mathrm{hr}$ and then equilibrated in $20 \%$ sucrose in $\mathrm{PBS}$ at $4^{\circ} \mathrm{C}$.

Immunohistochemistry. The brains were sectioned on a freezing microtome into four series ( $40 \mu \mathrm{m}$ thickness) for immunostaining only or five (30 $\mu \mathrm{m}$ thickness) series of sections for immunostaining plus in situ hybridization. Sections were washed in PBS (three changes) and incubated in PBS containing $0.3 \%$ Triton X-100 (PBT) and $0.2 \%$ sodium azide for $1 \mathrm{hr}$ at room temperature, followed by the primary antiserum: Fos, Ab-5, 1:150,000, rabbit (Oncogene Sciences, Uniondale, NY); CTB, 1:100,000, goat (List Biological); PHA-L, 1:10,000, goat (Vector Laboratories, Burlingame, CA); choline acetyltransferase (ChAT), 1:20,000, rabbit UO93 (gift from Dr. Louis Hersh, University of Kentucky); tyrosine hydroxylase (TH), 1:200, TE-101, rabbit (Eugene Tech, Eugene, OR); 5-HT, 1:10,000, goat (Chemicon, Temecula, CA) for $1 \mathrm{~d}$ at room temperature. Sections were then washed in PBS and incubated in biotinylated secondary antiserum (against appropriate species IgG; 1:1000 in PBT) for $1 \mathrm{hr}$, washed again in PBS, and incubated in avidin-biotin complex reagents for $1 \mathrm{hr}$. Sections were then washed again and incubated in a $0.06 \%$ solution of 3,3-diaminobenzidine tetrahydrochloride (DAB; Sigma, St. Louis, MO) plus $0.02 \% \mathrm{H}_{2} \mathrm{O}_{2}$. The sections were stained brown with DAB only or black by adding $0.05 \%$ cobalt chloride and $0.01 \%$ nickel ammonium sulfate to the DAB solutions. Fos and PHA-L staining was done using the black reaction, and CTB, ChAT,
5-HT, and TH staining was done using the brown reaction, as described previously (Chou et al., 2002). For double labeling of Fos and galanin mRNA, sections were stained for Fos with the brown reaction and then used for in situ hybridization.

In situ hybridization. The sections ( $30 \mu \mathrm{m}$ thickness) with Fos staining were acetylated and hybridized overnight $\left(55^{\circ} \mathrm{C}\right)$ with a ${ }^{35} \mathrm{~S}$-labeled cRNA probe synthesized from a plasmid containing the complete coding sequence of rat galanin (Vrontakis et al., 1987). After washing, the tissue was treated with RNase-A (Boehringer Mannheim, Indianapolis, IN) followed by a succession of washes of increasing stringency $(1 \mathrm{hr}$ each in $2 \times \mathrm{SSC} / 1 \mathrm{~mm} \mathrm{DTT}, 50^{\circ} \mathrm{C} ; 0.2 \times \mathrm{SSC} / 1 \mathrm{~mm} \mathrm{DTT}, 55^{\circ} \mathrm{C} ; 0.2 \times \mathrm{SSC} / 1 \mathrm{~mm}$ DTT, $60^{\circ} \mathrm{C}$ ), and then dehydrated in alcohols and air-dried. The sections were exposed to x-ray film (Eastman-Kodak, Rochester, NY) for 2-3 d, and then the slides were dipped in Kodak NTB-2 emulsion and exposed for 1 month. Slides were developed in Kodak D-19, fixed, and then dehydrated and coverslipped.

Cell counting. Fos-positive cells were counted in brightfield by an observer who was blinded to physiological treatment, in three consecutive sections (AP level: from $-0.3 \mathrm{~mm}$ to $-0.7 \mathrm{~mm}$ ) through the midpart of the VLPO and extended VLPO. The spacing between the sections was $160 \mu \mathrm{m}$. For experiments in which there was no galaninstaining present to define the borders of the VLPO, we constructed a set of counting boxes based on the distribution of galaninergic neurons: the VLPO cluster box was $300 \mu \mathrm{m}$ wide by $300 \mu \mathrm{m}$ high, placed along the base of the brain just medial to the diagonal band of Broca, as shown in Figure $1 B$. The medial extended VLPO box was medial to the VLPO cluster and $400 \mu \mathrm{m}$ wide by $300 \mu \mathrm{m}$ high (Fig. 1A); the dorsal extended VLPO box was $200 \mu \mathrm{m}$ wide by $300 \mu \mathrm{m}$ high, positioned above the VLPO cluster and medial extended VLPO boxes, and centered over their border. Because the mean diameter of Foslabeled nuclei was not different between experimental groups and controls, and we were interested only in relative cell numbers; we did not apply a correction factor for double counting (Guillery and Herrup, 1997).

\section{Statistical analysis}

We used Student's two-tailed $t$ test to compare the differences in the amounts of NREM and REM sleep time and in the numbers of Fospositive and double-labeled cells in the extended VLPO and VLPO cluster, under control conditions and after dark treatment.

For correlational analysis, the mean number of Fos-immunoreactive (Fos-ir) cells (per section per side) in the extended VLPO or the VLPO cluster was plotted against amounts of NREM sleep or REM sleep during the hour before perfusion. Pearson correlation coefficients and $p$ values were calculated.

\section{RESULTS}

\section{The relationship of Fos-positive neurons in the extended VLPO and sleep}

To determine the relationship of the Fos-ir cells in the extended VLPO and REM sleep, on the day of the experiment we exposed animals $(n=19)$ to dark from 7:00 A.M. to 10:00 A.M. (dark treatment) after 1 week on a $12 \mathrm{hr}$ light/dark cycle. Control animals $(n=10)$ were exposed to light from 7:00 A.M. to 10:00 A.M. as usual. Dark treatment increased REM sleep consistently across the $3 \mathrm{hr}$ period. NREM sleep occupied $65.2 \pm 4.2 \%$ (mean \pm SEM) and REM sleep occupied $13.1 \pm 4.9 \%$ of the first hour; NREM was $60.2 \pm 4.5 \%$ and REM was $16.1 \pm 2.1 \%$ in the second hour; and NREM was $56.1 \pm 4.5 \%$ and REM was $17.1 \pm$ $3.4 \%$ of the third hour. Over the third hour, dark treatment increased REM sleep by twofold over controls (dark, $17.1 \pm$ $3.4 \%$; light, $8.5 \pm 3.1 \%$; $p<0.001$ ), but had no significant effect on NREM sleep (dark, $56.1 \pm 4.5 \%$; light, $62.2 \pm 8.4 \% ; p>0.05$ ).

Dark-treated animals had a significant increase in the number of Fos-ir cells compared with controls in the medial extended VLPO $\left(22.9 \pm 1.3\right.$ vs $12.8 \pm 1.0$ cells $\cdot$ section $^{-1} \cdot$ side $^{-1} ; p<$ $0.01)$ and dorsal extended VLPO $(13 \pm 1.3$ vs $6.6 \pm 1.7$ cells $\cdot$ section $^{-1} \cdot$ side $\left.^{-1} ; p<0.01\right)$. However, the number of Fos-ir cells in the VLPO cluster did not differ (dark treatment, 


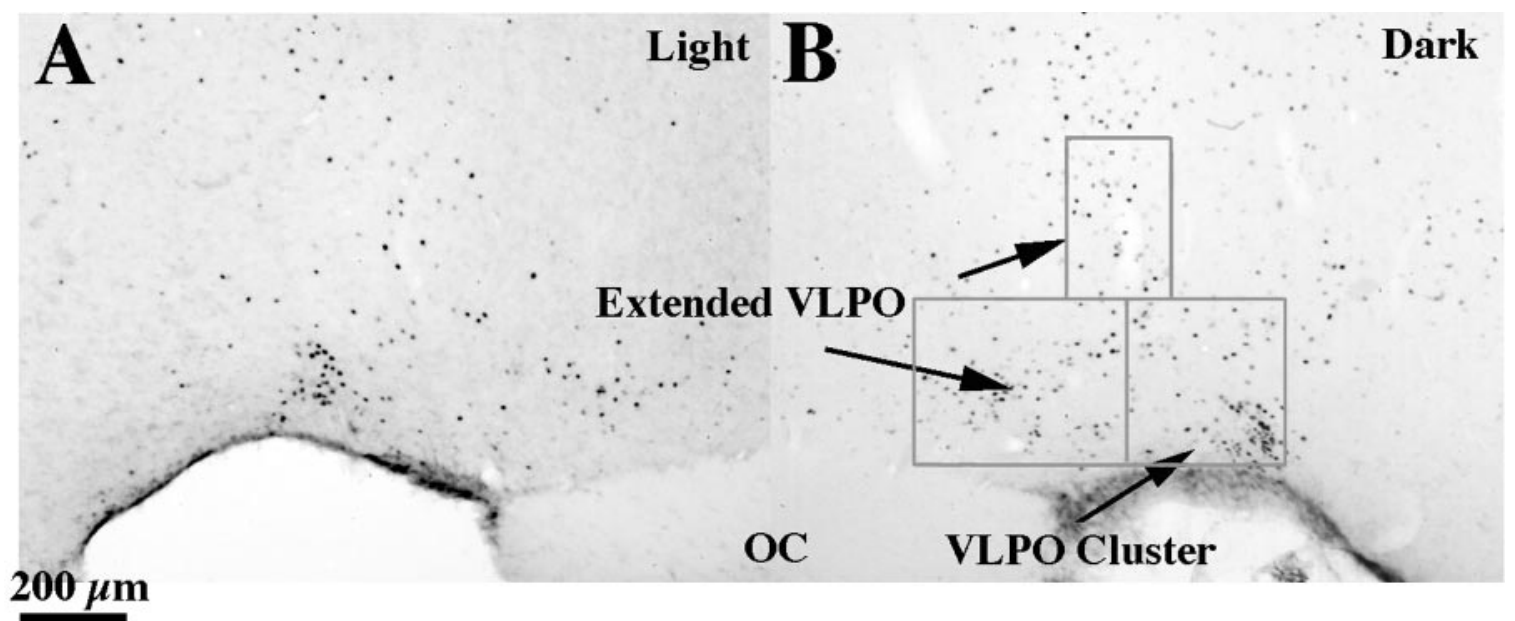

Figure 1. A pair of photomicrographs showing the distributions of Fos-ir cells in the extended VLPO and VLPO cluster in an animal exposed to light (12\% REM sleep, $A$ ) and in an animal exposed to dark treatment (30\% REM sleep, $B$ ) during the early part of the sleep cycle. The counting boxes used for the VLPO cluster and the dorsal and medial extended VLPO are shown in $B$. These sections are approximately at the level of AP -0.5 in Paxinos and Watson (1986). OC, Optic chiasm.

$20.4 \pm 5.3$ cells $\cdot$ section $^{-1} \cdot$ side $^{-1}$ vs controls, $18.0 \pm 5.5$

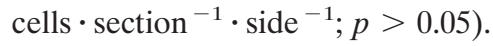

Putting together the light- and dark-treated animals, the number of Fos-ir cells in the medial extended VLPO $(r=0.76 ; p<$
$0.01)$ or dorsal extended VLPO $(r=0.71 ; p<0.01)$ was significantly correlated with REM sleep during the previous hour but was not significantly correlated with NREM sleep $(r=0.12,0.34$; $p>0.05$ ) (Fig. 2). In contrast, the number of VLPO cluster cells
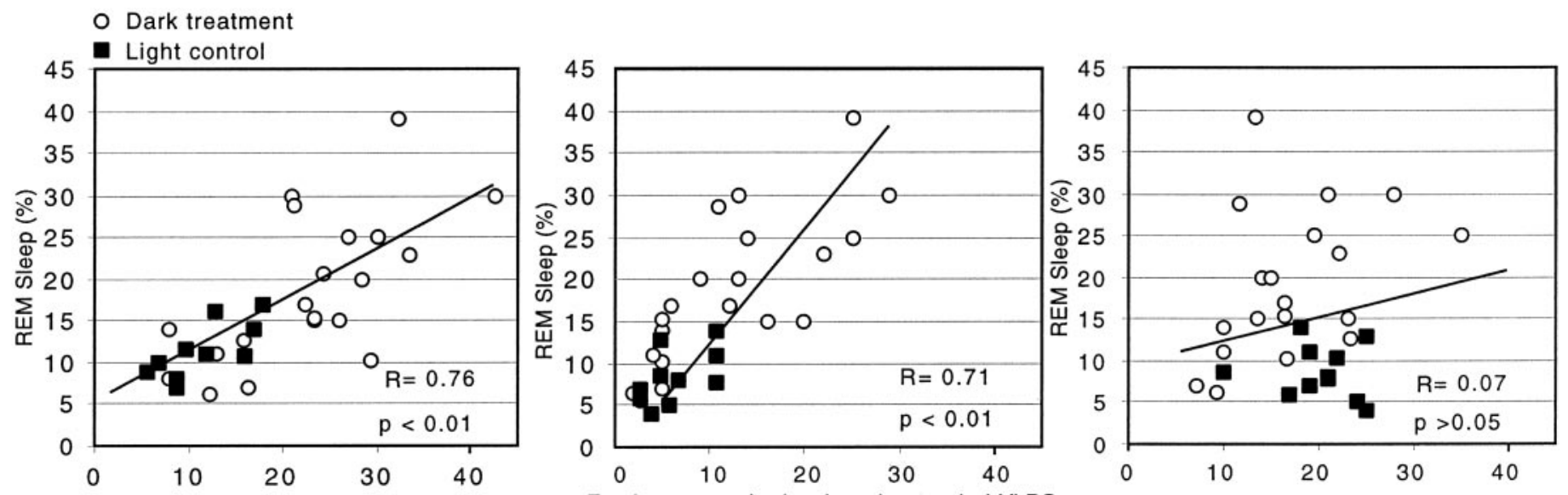

Fos-ir neurons in the VLPO cluster
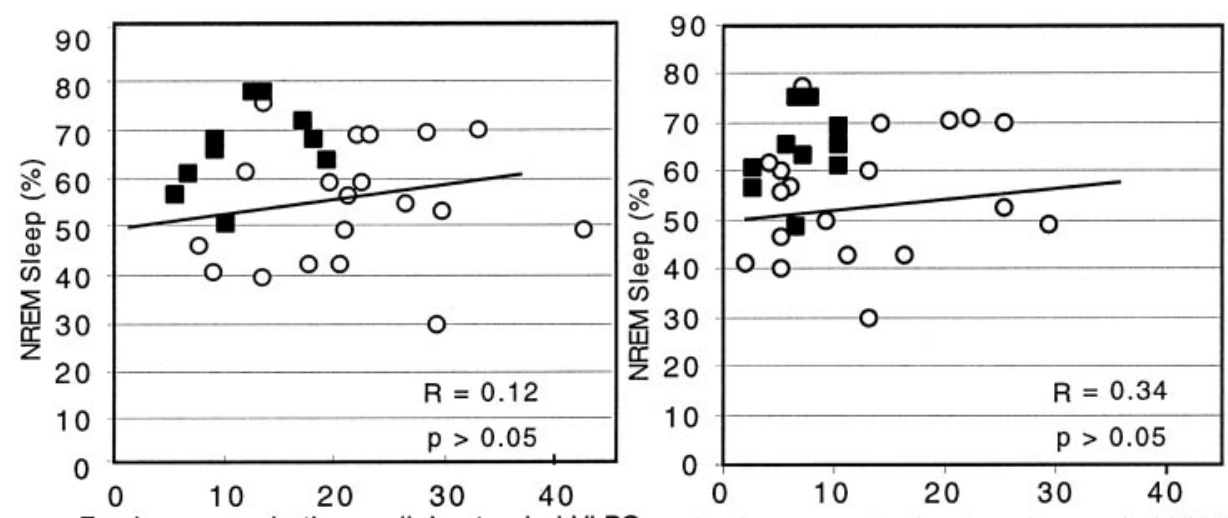

Fos-ir neurons in the dorsal extended VLPO

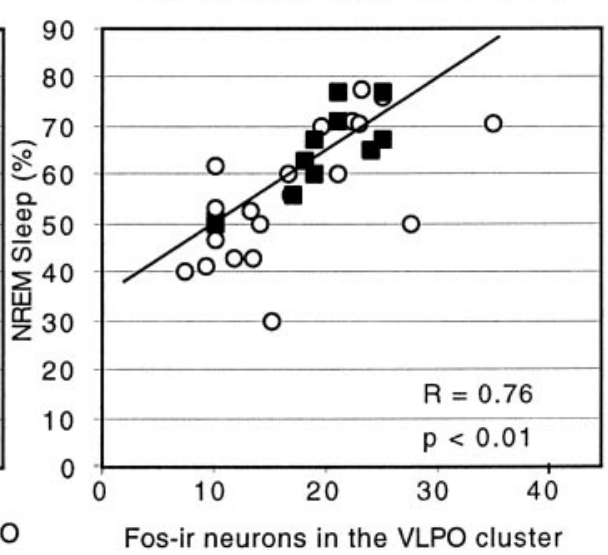

Figure 2. Correlation (illustrated by solid line) of the number of Fos-ir cells in the extended VLPO and VLPO cluster in light- and dark-treated animals with the amounts of REM sleep or NREM sleep that the animals experienced during the hour before perfusion. 


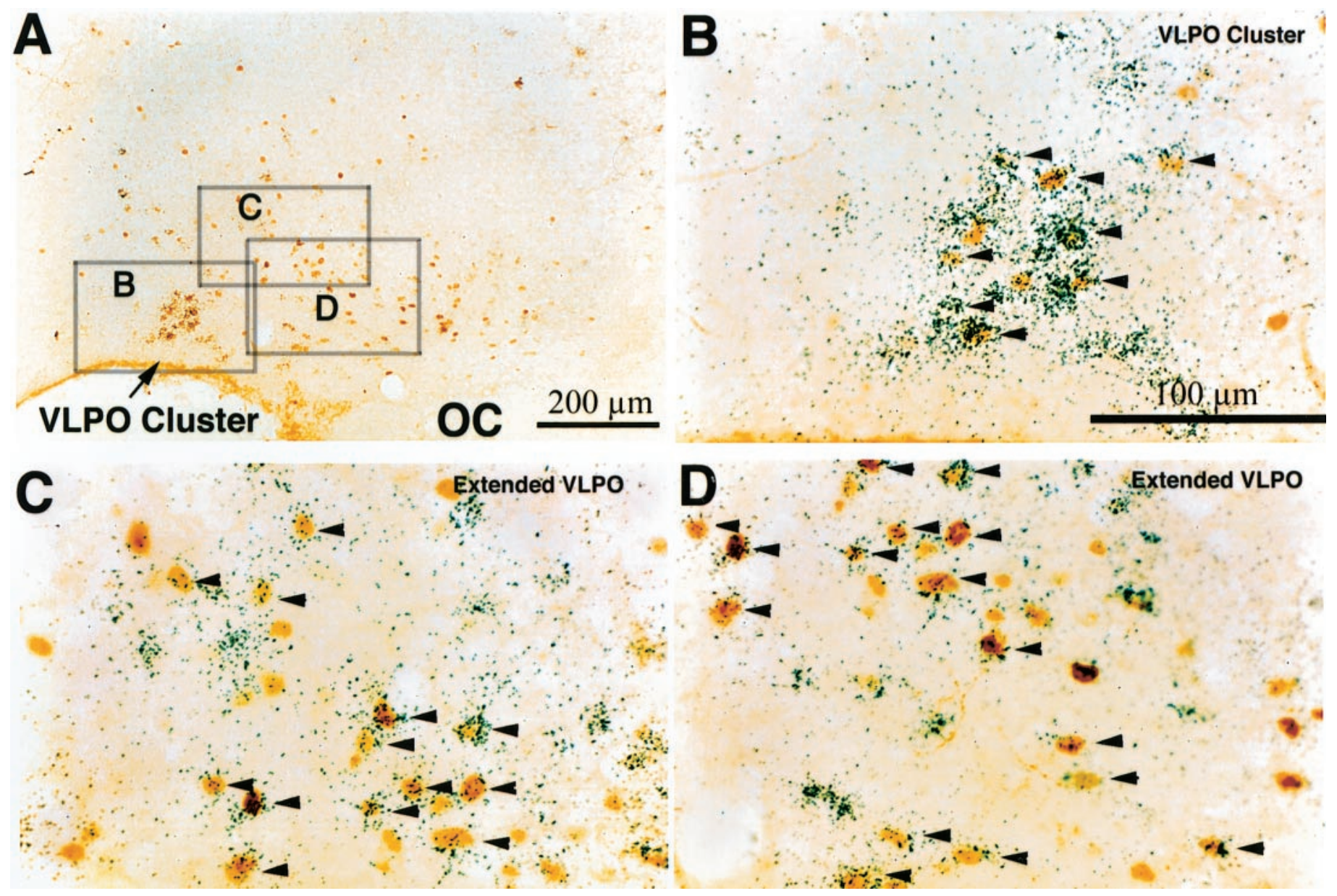

Figure 3. Photomicrographs showing dual labeling of Fos (brown immunostaining) and galanin mRNA (black silver grains representing in situ hybridization) in the extended VLPO and VLPO cluster. Arrowheads indicate double-labeled cells. Many Fos-ir cells in the extended VLPO and particularly in the VLPO cluster contain galanin mRNA. $A$ shows the VLPO complex with boxes that are shown at higher magnification in $B-D$. Note that these fields are not equivalent to the counting boxes shown in Figure 1. OC, Optic chiasm.

was not significantly correlated with REM sleep $(r=0.07 ; p>$ $0.05)$ (Fig. 2); however, it was significantly correlated with NREM sleep $(r=0.76 ; p<0.01)$ (Fig. 2).

\section{Sleep-active cells in the extended VLPO and VLPO cluster of dark-treated animals contain galanin}

The relationship of Fos-ir cells and neurons containing galanin mRNA in the extended VLPO was determined in rats that received dark treatment $(n=10)$ versus controls $(n=7)$ (Fig. 3). In the dark-treated animals, $90.2 \pm 8.2 \%$ of the Fos-positive cells in the VLPO cluster and $60.5 \pm 6.1 \%$ of Fos cells in the extended VLPO contained galanin mRNA. In control rats, a high percentage of Fos-ir cells also contained galaninergic mRNA in the VLPO cluster $(93.2 \pm 9.5 \%)$ and the extended VLPO (80.7 \pm $10.2 \%)$.

\section{Relationship of Fos-positive and retrogradely labeled cells after injections of CTB into the LDT, LC, and DRN after dark treatment}

To determine whether the cells in the extended VLPO and VLPO cluster that project to the LDT, DRN, and LC expressed Fos during REM sleep, we injected the retrograde tracer CTB into the region containing the LDT $(n=10)$, LC $(n=12)$, or DRN (central area, $n=10$; lateral wing, $n=9$ ). The animals were then perfused as described above after dark treatment, and the brains were stained for CTB (brown) and Fos (black). All cell counts were done on the ipsilateral side of the brain, which contained the heaviest retrograde labeling. Animals in this series were analyzed if they spent $>50 \%$ of the hour before death in NREM sleep and $>10 \%$ in REM sleep.

In seven rats that had injections into the LDT (Fig. 4), many more CTB-labeled cells were found in the extended VLPO $(5.8 \pm 2.5$ cells/ipsilateral section; $p<0.05)$ than in the VLPO cluster $(2.8 \pm 0.9$ cells/ipsilateral section). Of CTB-labeled cells, $62.2 \pm 19.5 \%$ in the extended VLPO and $95.0 \pm 5.0 \%$ in the VLPO cluster were Fos-positive (Fig. 5). Three control rats in which the CTB injections were dorsal to the LDT showed no retrogradely labeled cells in either the extended VLPO or the VLPO cluster.

Five of 12 injections aimed at the LC largely filled the nucleus; in the rest of the animals, the injections were medial, lateral, or ventral to the LC, and these rats were used as anatomical controls. In the five sleeping rats with injections filling the LC, more CTB-labeled cells were found in the extended VLPO than in the VLPO cluster $(6.5 \pm 1.5$ vs $3.0 \pm 1.4$ cells/ipsilateral section; $p<$ $0.05)$. In these dark-treated animals, $46.6 \pm 7.4 \%$ of the CTBlabeled cells in the extended VLPO and $56.0 \pm 3.1 \%$ of CTBlabeled cells in the VLPO cluster were Fos-positive (Fig. 5). We 


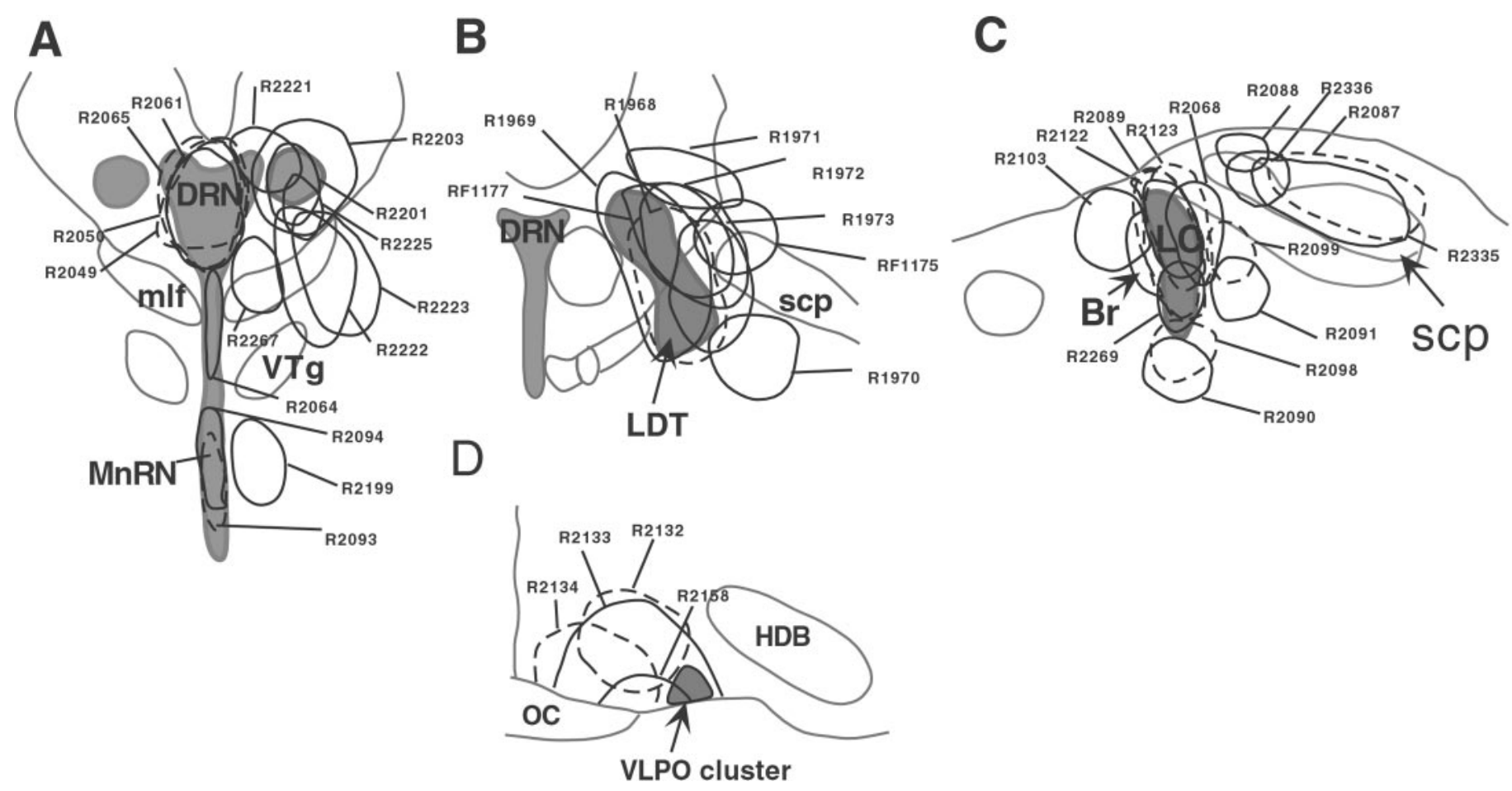

Figure 4. Camera lucida drawings showing selected injection sites (black solid and dashed lines) of CTB in the region of the DRN (A), LDT (B), and LC $(C)$ as well as four injection sites of PHA-L in the VLPO region $(D)$. Gray shading shows borders of key nuclei; gray lines show other brain structures. $B r$, Barrington's nucleus; $H D B$, horizontal limb of the nucleus of the diagonal band of Broca; $m l f$, medial longitudinal fasciculus; $M n R n$, median raphe nucleus; $O C$, optic chiasm; scp, superior cerebellar peduncle; $V T g$, ventral tegmental nucleus.

also noticed CTB-labeled cells scattered in the medial preoptic area and dorsolateral preoptic area, but these cells were not Fos-positive during sleep (Fig. 5). The injections in the areas immediately medial (R2103), lateral (R2091 and R2099), or ventral (R2090 and R2098) to the LC did not retrogradely label cells in the extended VLPO or the VLPO cluster (Fig. 4).

In 10 rats with injections of CTB into the central part of the DRN, more retrogradely labeled cells were found in the extended VLPO than in the VLPO cluster $(5.5 \pm 2.1$ vs $2.4 \pm 1.1$ cells/ ipsilateral section; $p<0.05)$. Only $15.0 \pm 8.2 \%$ of CTB-labeled cells in the extended VLPO and $12.5 \pm 4.5 \%$ of CTB-labeled cells in the VLPO cluster were Fos-positive (Fig. 5). We found numerous CTB-labeled cells in the diagonal band nucleus, the median preoptic nucleus, and the dorsolateral preoptic area, but very few cells in these regions were Fos-positive during sleep.

Four rats that had CTB injections into the lateral wing of the dorsal raphe nucleus (also called the paradorsal raphe nucleus; see injection 2203 in Fig. 4A) and were asleep for most of the hour before perfusion (NREM, $53.5 \pm 5.6 \%$; REM, $18.2 \pm 4.3 \%$ ) showed retrogradely labeled cells in the extended VLPO (3.0 \pm 0.8 cells/ipsilateral section) and VLPO cluster $(3.0 \pm 0.81$ cells/ ipsilateral section). In these animals, a large percentage of retrogradely labeled neurons was also Fos-positive in the VLPO cluster $(64.2 \pm 27.4 \%)$ and extended VLPO $(56.5 \pm 7.0 \%)$. Two rats that had injections ventral to the lateral wing of the DRN (experiments R2222 and R2223) (Fig. 4A) showed no doublelabeled cells in the VLPO cluster and very few in the extended VLPO. Two other rats that had injections into the lateral wing of the DRN and $>70 \%$ wakefulness during the hour before perfusion also showed no double-labeled cells in the extended VLPO and VLPO cluster.

\section{Anterograde tracing of inputs from the extended VLPO and VLPO cluster to the LDT, DRN, and LC}

To determine the relationship of efferents from the extended VLPO and VLPO cluster to chemically identified neurons in the LDT, DRN, and LC, PHA-L was injected into the extended VLPO and the VLPO cluster in five rats, and sections through the brainstem were immunostained for PHA-L (black) axons and with antisera against 5-HT, ChAT, or TH (brown).

The VLPO complex was successfully labeled in four cases: two involving the cluster plus part of the extended VLPO and two involving primarily the extended VLPO (Fig. 4D). All of them gave rise to a similar pattern of efferent projection. In case R2133, the PHA-L injection filled the VLPO cluster and dorsal extended VLPO and partially filled the medial extended VLPO. Labeled efferents terminated extensively in the LDT, LC, and DRN, as well as in the median raphe nucleus.

In the LDT, labeled axons primarily terminated in the dorsal LDT region. The efferent terminal field only partially overlapped with the region occupied by cholinergic cells. Double staining showed that labeled terminals did not form appositions with the ChAT-ir cell bodies or proximal dendrites in the LDT, but rather appeared to terminate in the region between the cholinergic cell bodies (Fig. 6). Using Nissl staining, we found that some terminals apposed small-sized cells in the LDT region. Compared with the LDT, relatively few labeled axons terminated in the cholinergic pedunculopontine tegmental nucleus (PPT) and the efferent terminals did not appose cholinergic cells.

In the LC, terminal boutons were located predominantly in the ventral LC, especially in the region containing a dense bundle of 

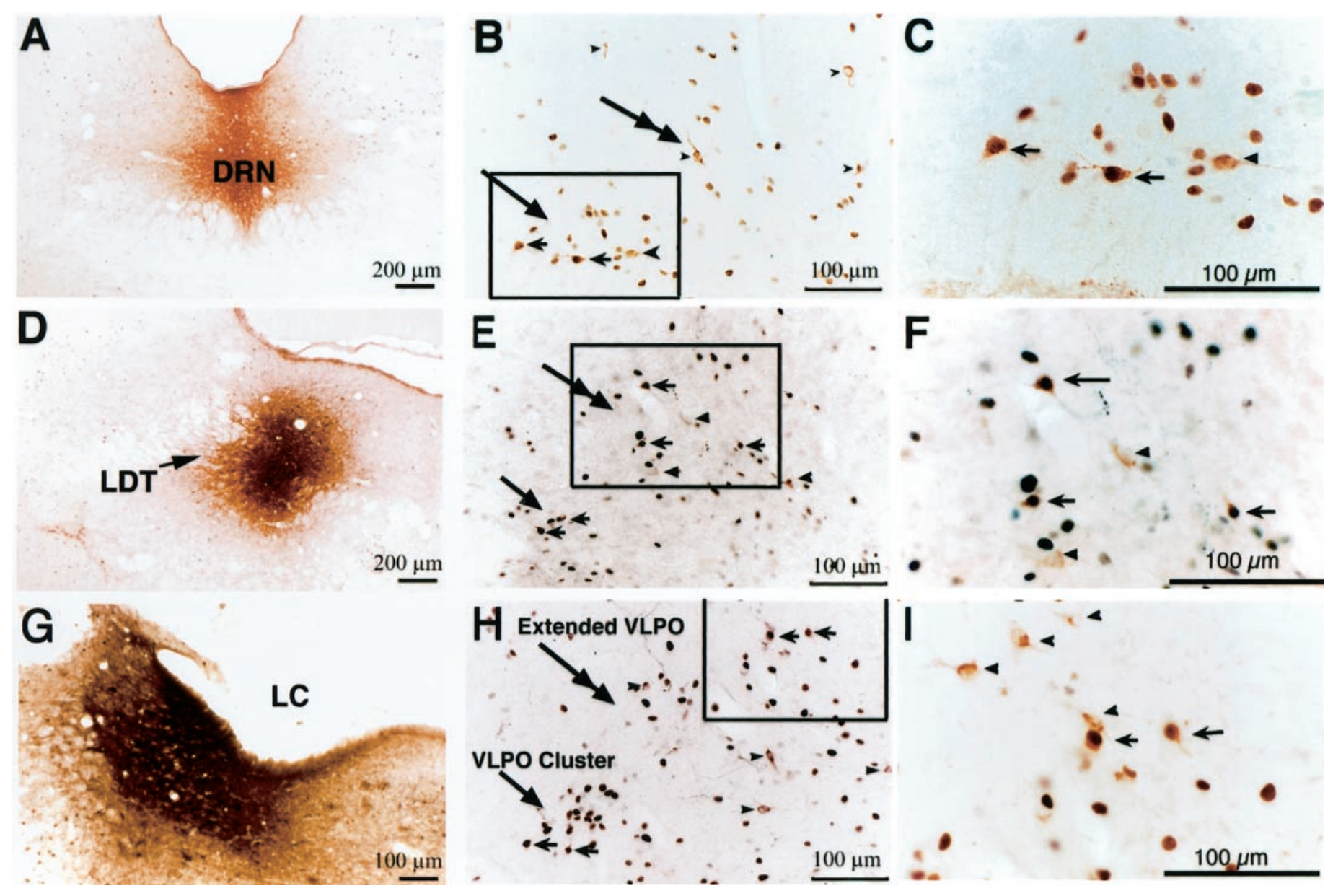

Figure 5. Dual labeling of CTB retrograde transport (brown) and Fos expression (black) in cells within the extended VLPO and VLPO cluster (B, E, $H)$ after the injections of CTB into the central DRN ( $A$, experiment R2049), LDT ( $D$, experiment R1969), and LC ( $G$, experiment R2219), respectively, in the rats exposed to $3 \mathrm{hr}$ of darkness. In $B, E$, and $H$, the VLPO cluster is identified by a large arrow and the extended VLPO by a large double-headed arrow. The rectangular boxes identify the fields that are magnified in $C, F$, and $I$, respectively. Double-labeled cells in the extended VLPO and VLPO cluster are indicated by small arrows and single CTB labeled cells are indicated by small arrowheads.

noradrenergic dendrites, where many boutons apposed TH-ir dendrites. In addition, labeled terminals also were apposed to the noradrenergic cell bodies in the core of the LC (Fig. 6).

In the DRN, efferent terminals were heavily distributed throughout the nucleus and especially in its lateral wing. Double staining demonstrated that many labeled terminals apposed serotoninergic cell bodies and dendrites in the DRN (Fig. 6), although many terminated on unlabeled (presumably nonserotoninergic) cells. Labeled axons also terminated heavily in the ventrolateral periaqueductal gray matter (PAG), dorsolateral to the lateral wing of the DRN.

Cases in which the injections involved the extended VLPO but avoided the VLPO cluster (e.g., experiments R2132 and R2134) (Fig. 4D) showed very similar distributions of efferent terminals with respect to appositions onto the monoaminergic and cholinergic neurons in the midbrain and pons. The only major exception was a relatively smaller number of terminals onto serotoninergic neurons in the central DRN in these cases.

\section{DISCUSSION}

Our principal findings were that in dark-treated rats with increased amounts of REM sleep, the number of Fos-positive cells in the extended VLPO was positively correlated with REM sleep time but was not correlated with NREM sleep time. In contrast, the number of Fos-positive cells in the VLPO cluster was positively correlated with NREM sleep time but was not correlated with REM sleep time. A high percentage of Fos-positive cells in the VLPO cluster $(>90 \%)$ and the extended VLPO $(>60 \%)$ contained galanin mRNA. By injecting retrograde tracer into the LDT and LC, we found that the extended VLPO of dark-treated rats contained more retrogradely labeled cells than the VLPO cluster, and that $\sim 50 \%$ of the labeled cells were Fos-positive in dark-treated sleeping animals. Although we found that numerous retrogradely labeled cells in the extended VLPO project to the central part of the DRN, a relatively small number of them (12-15\%) were Fos-positive during sleep in dark-treated animals. However, injections of CTB into the lateral wing of the DRN yielded more retrogradely labeled and double-labeled cells (CTB plus Fos) in the VLPO cluster (64\%). Anterograde tracing showed that the efferents of the extended VLPO and VLPO cluster apposed the serotoninergic cell bodies and proximal dendrites in the DRN especially in the lateral wing region and the noradrenergic cell bodies in the LC, but there were few appositions with the cholinergic cells in the LDT or PPT. We hypoth- 


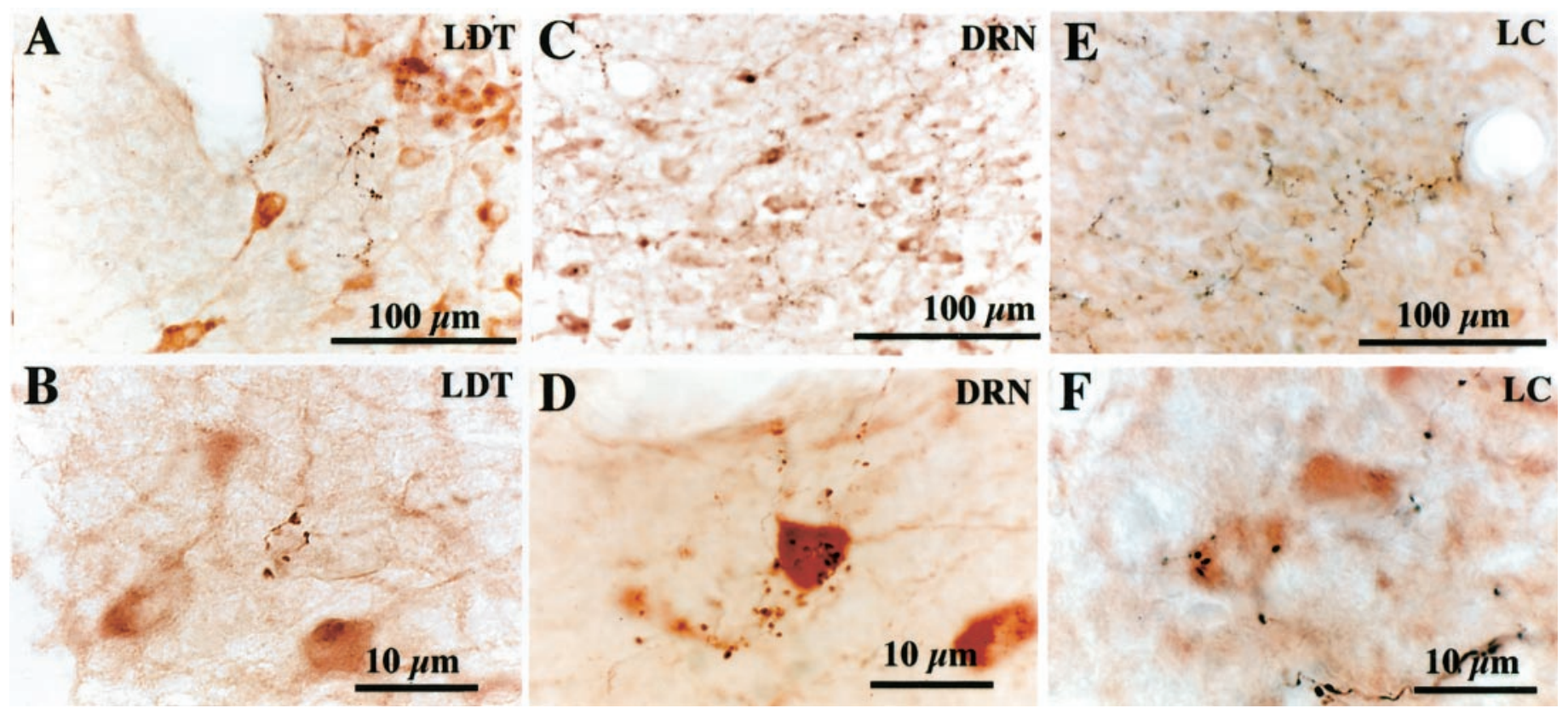

Figure 6. Photomicrographs showing the relationships of anterogradely labeled efferent axons (black) from the extended VLPO and VLPO cluster with neurons in the DRN, LDT, and LC that are stained (brown) for serotonin, choline acetyltransferase, or tyrosine hydroxylase, respectively. In $A$, the efferent terminals concentrate dorsal to the cluster of the cholinergic cells in the LDT. Occasionally we found that terminal boutons were near choline acetyltransferase-immunoreactive neurons such as in $B$; however careful observation indicated that such boutons were not on the same plane as the cholinergic cell body. In $C$ and $D$, efferent terminal boutons clearly appose serotonin-immunoreactive neurons in the DRN. $E$ and $F$ show labeled efferent axons apposing tyrosine hydroxylase-immunoreactive neurons in the LC.

esize that the extended VLPO may enhance REM sleep by its influence on the LDT, DRN, and LC.

\section{Technical considerations}

Four methods have been used previously to study brain activity during enhanced REM sleep in rats and cats: auditory stimulation, recovery from REM sleep deprivation (platform method), injection of carbachol into the brainstem, and dark treatment. Using the first two methods, Merchant-Nancy et al. (1995) found significant Fos induction in the brainstem (nucleus of the solitary tract, LDT, PPT, and parabrachial nucleus) and diencephalon (suprachiasmatic nucleus, lateral hypothalamus), and amygdaloid nucleus. Injection of carbachol into a region of the pontine reticular formation that receives the LDT/PPT cholinergic efferents (Semba et al., 1990) causes prolonged and persistent REM sleep in cats and rats (Shiromani et al., 1992, 1995; Marks and Birabil, 1998; Horner and Kubin, 1999) and produces Fos in both cholinergic and noncholinergic cells such as GABAergic ones in the LDT and PPT (Shiromani et al., 1992, 1995; Yamuy et al., 1998; Xi et al., 1999; Torterolo et al., 2001). Similar Fos expression patterns in the LDT/PPT have also been observed during recovery from REM sleep deprivation (Maloney et al., 1999). In contrast, Fos immunoreactivity was not expressed in the serotoninergic DRN cells and noradrenergic LC cells during REM sleep (Maloney et al., 1999). These results are consistent with the hypothesis that REM sleep is triggered by activity of cholinergic LDT/PPT neurons, occurring in association with inactivity of the monoaminergic cells in the DRN and LC (Maloney et al., 1999, 2000; see below). However, these previous studies did not examine the hypothalamus in detail.

We chose to use dark treatment to induce REM sleep because it does not involve inherently stressful or invasive procedures. The mechanism by which dark treatment triggers REM sleep is not clear, although this phenomenon appears to occur in albino but not pigmented rats (Benca et al., 1991, 1998). Direct retinal projections have been found to the sleep-active, galaninergic cells in the extended VLPO and VLPO cluster (Lu et al., 1999) and to the DRN (Shen and Semba, 1994; Fite et al., 1999). This pathway could potentially mediate the effect of dark treatment on REM sleep. However, Miller et al. (1998) reported that lesions of the pretectum and superior colliculus could diminish the darkmediated increase in REM sleep.

We realize that demonstration of synaptic contacts from the extended VLPO and VLPO cluster with neurons in the brainstem will require electron microscopy. However, the spatial relationship of the terminal boutons with cell bodies in our materials suggests the likelihood of synaptic contacts.

\section{Brainstem regulation of REM sleep}

It is well established that the cholinergic cells in the LDT/PPT, which show increased firing rates during REM sleep and are almost inactive during NREM sleep, play a central role in generating REM sleep (Kayama et al., 1992; Sakai and Koyama, 1996). Lesions of the LDT abolish REM sleep in cats (Webster and Jones, 1988), and electrical stimulation of the LDT or glutamate injection into the PPT increases REM sleep (Thakkar et al., 1996; Datta and Siwek, 1997). Injection of the cholinergic agonist carbachol into the medial pontine reticular formation, a target of the PPT (Rye et al., 1987), induces prolonged and persistent REM sleep in cats and rats (Shiromani et al., 1992, 1995; Marks and Birabil, 1998).

Serotoninergic cells in the DRN and noradrenergic cells in the LC are active during wakefulness, less active during NREM sleep, and inactive during REM sleep (Heym et al., 1982; Fornal et al., 1985; Sakai, 1986; Reiner and McGeer, 1987; Yamuy et al., 1995, 1998; Thakkar et al., 1998; Gervasoni et al., 2000). Both cell 
groups project to the LDT/PPT (Semba and Fibiger, 1992; Honda and Semba, 1994; Leonard et al., 1995; Steininger et al., 1997) where they are thought to inhibit the cholinergic neurons. The inhibition of serotoninergic and noradrenergic neurons by the extended VLPO would thereby promote REM sleep (Jones, 1991; Hobson et al., 1998; Crochet and Sakai, 1999).

The quiescence of sertoninergic cells during REM sleep is caused by GABAergic inputs (Levine and Jacobs, 1992; Wang et al., 1992; Nitz and Siegel, 1997a; Gervasoni et al., 2000). Because virtually all VLPO and extended VLPO neurons that contain galanin also contain GABA, the extended VLPO may be a critical source of inhibition of monoaminergic regions during REM sleep (Sherin et al., 1998; Gervasoni et al., 2000; J. E. Sherin and C. B. Saper, unpublished observations). Stimulation of the preoptic area by warming, which increases the firing of many sleep-active neurons, inhibits firing activity in the serotoninergic cells in the DRN (Guzman-Marin et al., 2000). Similarly GABAergic control of the LC is also thought to derive from the preoptic area (Luppi et al., 1995; Nitz and Siegel, 1997b; Sherin et al., 1998; Luppi et al., 1999). Sherin et al. (1998) attributed this projection primarily to the VLPO, but their injections of anterograde tracer included the medial and dorsal extended VLPO as well as the VLPO cluster. Our results indicate that much of the input to the DRN and LC attributed to the VLPO actually originates from the extended VLPO.

We also identified an intense projection from the extended VLPO and VLPO cluster to the ventrolateral PAG. The ventrolateral PAG contains GABAergic cells (Gervasoni et al., 2000), and injection of a GABAergic agonist into the ventrolateral periaqueductal gray matter increases REM sleep (Sastre et al., 1996). The mechanism by which GABAergic cells in the periaqueductal gray matter may contribute to REM sleep remains to be determined, but our finding suggests another potential pathway by which the extended VLPO and VLPO cluster may influence REM sleep.

\section{Preoptic regulation of REM and NREM sleep}

The sleep-active cells in the VLPO cluster were originally defined by their expression of Fos protein during sleep, their expression of the neurotransmitters galanin and GABA, and their projection to the histaminergic cells in the TMN (Sherin et al., 1996, 1998). Our previous studies (Sherin et al., 1998; Lu et al., 2000; Gaus et al., 2002) also found that many cells extending beyond the VLPO cluster in a dorsal and medial direction possess the same qualities, and we speculated that they might project topographically to different targets. We found that lesions of the VLPO cluster primarily were correlated with loss of NREM sleep, whereas lesions of the extended VLPO correlated with loss of REM sleep (Lu et al., 2000). Here we show in dark-treated rats that the sleep-active cells in the extended VLPO are galaninergic cells, that their activity is highly correlated with REM sleep, and that they do indeed have slightly different projections from neurons in the VLPO cluster, which are consistent with a role in regulating REM sleep.

During NREM sleep, the sleep-active neurons in the VLPO cluster would inhibit the activity of the cells in the TMN, DRN, and LC by releasing galanin and GABA, thus maintaining slowwave sleep. During the transitions from NREM to REM sleep, the firing of DRN and LC is further decreased (Heym et al., 1982; Fornal et al., 1985; Sakai, 1986; Reiner and McGeer, 1987). We propose that this transition may be attributable at least in part to the recruitment of inhibitory neurons in the extended VLPO that further decrease LC and DRN firing, thus disinhibiting the LDT and PPT cholinergic cells. In addition, if extended VLPO efferents end on inhibitory interneurons in the LDT/PPT, they could further promote their firing during the transition to REM sleep. The connections of the extended VLPO neurons and their REMactive pattern would make them prime candidates to fulfill this role.

\section{REFERENCES}

Alfoldi P, Franken P, Tobler I, Borbely AA (1991) Short light-dark cycles influence sleep stages and EEG power spectra in the rat. Behav Brain Res 43:125-131.

Benca RM, Bergmann BM, Leung C, Nummy D, Rechtschaffen A (1991) Rat strain differences in response to dark pulse triggering of paradoxical sleep. Physiol Behav 49:83-87.

Benca RM, Gilliland MA, Obermeyer WH (1998) Effects of lighting conditions on sleep and wakefulness in albino Lewis and pigmented Brown Norway rats. Sleep 21:451-460.

Chou TC, Bjorkum AA, Gaus SE, Lu J, Scammell TE, Saper CB (2002) Afferents to the ventrolateral preoptic nucleus. J Neurosci 22:977-990.

Crochet S, Sakai K (1999) Effects of microdialysis application of monoamines on the EEG and behavioural states in the cat mesopontine tegmentum. Eur J Neurosci 11:3738-3752.

Datta S, Siwek DF (1997) Excitation of the brain stem pedunculopontine tegmentum cholinergic cells induces wakefulness and REM sleep. J Neurophysiol 77:2975-2988.

Fite KV, Janusonis S, Foote W, Bengston L (1999) Retinal afferents to the dorsal raphe nucleus in rats and Mongolian gerbils. J Comp Neurol 414:469-484.

Fornal C, Auerbach S, Jacobs BL (1985) Activity of serotonincontaining neurons in nucleus raphe magnus in freely moving cats. Exp Neurol 88:590-608

Gaus SE, Strecker RE, Tate BA, Parker RA, Saper CB (2002) Ventrolateral preoptic nucleus contains sleep-active, galaninergic neurons across the mammalian spectrum. Neuroscience, in press.

Gervasoni D, Peyron C, Rampon C, Barbagli B, Chouvet G, Urbain N, Fort P, Luppi PH (2000) Role and origin of the GABAergic innervation of dorsal raphe serotonergic neurons. J Neurosci 20:4217-4225.

Guillery RW, Herrup K (1997) Quantification without pontification: choosing a method for counting objects in sectioned tissues. J Comp Neurol 386:2-7.

Guzman-Marin R, Alam MN, Szymusiak R, Drucker-Colin R, Gong H, McGinty D (2000) Discharge modulation of rat dorsal raphe neurons during sleep and waking: effects of preoptic/basal forebrain warming. Brain Res 875:23-34.

Heym J, Steinfels GF, Jacobs BL (1982) Activity of serotonin-containing neurons in the nucleus raphe pallidus of freely moving cats. Brain Res 251:259-276.

Hobson JA, Stickgold R, Pace-Schott EF (1998) The neuropsychology of REM sleep dreaming. NeuroReport 9:R1-R14.

Honda T, Semba K (1994) Serotonergic synaptic input to cholinergic neurons in the rat mesopontine tegmentum. Brain Res 647:299-306.

Horner RL, Kubin L (1999) Pontine carbachol elicits multiple rapid eye movement sleep-like neural events in urethane-anaesthetized rats. Neuroscience 93:215-226.

Jones BE (1991) The role of noradrenergic locus coeruleus neurons and neighboring cholinergic neurons of the pontomesencephalic tegmentum in sleep-wake states. Prog Brain Res 88:533-543.

Kayama Y, Ohta M, Jodo E (1992) Firing of "possibly" cholinergic neurons in the rat laterodorsal tegmental nucleus during sleep and wakefulness. Brain Res 569:210-220.

Koyama Y, Hayaishi O (1994) Firing of neurons in the preoptic/anterior hypothalamic areas in rat: its possible involvement in slow wave sleep and paradoxical sleep. Neurosci Res 19:31-38.

Leonard CS, Kerman I, Blaha G, Taveras E, Taylor B (1995) Interdigitation of nitric oxide synthase-, tyrosine hydroxylase-, and serotonincontaining neurons in and around the laterodorsal and pedunculopontine tegmental nuclei of the guinea pig. J Comp Neurol 362:411-432.

Levine ES, Jacobs BL (1992) Neurochemical afferents controlling the activity of serotonergic neurons in the dorsal raphe nucleus: microiontophoretic studies in the awake cat. J Neurosci 12:4037-4044.

Lu J, Shiromani P, Saper CB (1999) Retinal input to the sleep-active ventrolateral preoptic nucleus in the rat. Neuroscience 93:209-214.

Lu J, Greco M, Shiromani P, Saper CB (2000) Effects of the lesions of the ventrolateral preoptic nucleus on NREM and REM sleep. J Neurosci 20:3830-3842.

Luppi PH, Aston-Jones G, Akaoka H, Chouvet G, Jouvet M (1995) Afferent projections to the rat locus coeruleus demonstrated by retrograde and anterograde tracing with cholera-toxin B subunit and Phaseolus vulgaris leucoagglutinin. Neuroscience 65:119-160.

Luppi PH, Gervasoni D, Peyron C, Rampon C, Barbagli B, Boissard R, 
Fort P (1999) Norepinephrine and REM sleep. In: Rapid eye movement sleep (Mallick BN, Inoue S, eds), pp 107-122. New Delhi, India: Narosa.

Maloney KJ, Mainville L, Jones BE (1999) Differential c-Fos expression in cholinergic, monoaminergic, and GABAergic cell groups of the pontomesencephalic tegmentum after paradoxical sleep deprivation and recovery. J Neurosci 19:3057-3072.

Maloney KJ, Mainville L, Jones BE (2000) c-Fos expression in GABAergic, serotonergic, and other neurons of the pontomedullary reticular formation and raphe after paradoxical sleep deprivation and recovery. J Neurosci 20:4669-4679.

Marks GA, Birabil CG (1998) Enhancement of rapid eye movement sleep in the rat by cholinergic and adenosinergic agonists inf used into the pontine reticular formation. Neuroscience 86:29-37.

Merchant-Nancy H, Vazquez J, Garcia F, Drucker-Colin R (1995) Brain distribution of c-fos expression as a result of prolonged rapid eye movement (REM) sleep period duration. Brain Res 681:15-22.

Miller AM, Obermeyer WH, Behan M, Benca RM (1998) The superior colliculus-pretectum mediates the direct effects of light on sleep. Proc Natl Acad Sci USA 95:8957-8962.

Nitz D, Siegel J (1997a) GABA release in the dorsal raphe nucleus: role in the control of REM sleep. Am J Physiol 273:R451-R455.

Nitz D, Siegel JM (1997b) GABA release in the locus coeruleus as a function of sleep/wake state. Neuroscience 78:795-801.

Osaka T, Matsumura H (1994) Noradrenergic inputs to sleep-related neurons in the preoptic area from the locus coeruleus and the ventrolateral medulla in the rat. Neurosci Res 19:39-50.

Paxinos G, Watson C (1986) The rat brain in stereotaxic coordinates. San Diego: Academic.

Reiner PB, McGeer EG (1987) Electrophysiological properties of cortically projecting histamine neurons of the rat hypothalamus. Neurosci Lett 73:43-47.

Rye DB, Saper CB, Lee HJ, Wainer BH (1987) Pedunculopontine tegmental nucleus of the rat: cytoarchitecture, cytochemistry, and some extrapyramidal connections of the mesopontine tegmentum. J Comp Neurol 259:483-528.

Sakai K (1986) Central mechanisms of paradoxical sleep. Brain Dev $8: 402-407$.

Sakai K, Koyama Y (1996) Are there cholinergic and non-cholinergic paradoxical sleep-on neurones in the pons? NeuroReport 7:2449-2453.

Sastre JP, Buda C, Kitahama K, Jouvet M (1996) Importance of the ventrolateral region of the periaqueductal gray and adjacent tegmentum in the control of paradoxical sleep as studied by muscimol microinjections in the cat. Neuroscience 74:415-426.

Semba K, Fibiger HC (1992) Afferent connections of the laterodorsal and the pedunculopontine tegmental nuclei in the rat: a retro- and antero-grade transport and immunohistochemical study. J Comp Neurol 323:387-410.

Semba K, Reiner PB, Fibiger HC (1990) Single cholinergic mesopontine tegmental neurons project to both the pontine reticular formation and the thalamus in the rat. Neuroscience 38:643-654.

Shen H, Semba K (1994) A direct retinal projection to the dorsal raphe nucleus in the rat. Brain Res 635:159-168.

Sherin JE, Shiromani PJ, McCarley RW, Saper CB (1996) Activation of ventrolateral preoptic neurons during sleep. Science 271:216-219.
Sherin JE, Elmquist JK, Torrealba F, Saper CB (1998) Innervation of histaminergic tuberomammillary neurons by GABAergic and galaninergic neurons in the ventrolateral preoptic nucleus of the rat. J Neurosci 18:4705-4721.

Shiromani PJ, Kilduff TS, Bloom FE, McCarley RW (1992) Cholinergically induced REM sleep triggers Fos-like immunoreactivity in dorsolateral pontine regions associated with REM sleep. Brain Res 580:351-357.

Shiromani PJ, Malik M, Winston S, McCarley RW (1995) Time course of Fos-like immunoreactivity associated with cholinergically induced REM sleep. J Neurosci 15:3500-3508.

Steininger TL, Wainer BH, Blakely RD, Rye DB (1997) Serotonergic dorsal raphe nucleus projections to the cholinergic and noncholinergic neurons of the pedunculopontine tegmental region: a light and electron microscopic anterograde tracing and immunohistochemical study. J Comp Neurol 382:302-322.

Steininger TL, Gong H, McGinty D, Szymusiak R (2001) Subregional organization of preoptic area/anterior hypothalamic projections to arousal-related monoaminergic cell groups. J Comp Neurol 429:638-653.

Szymusiak R, Alam N, Steininger TL, McGinty D (1998) Sleep-waking discharge patterns of ventrolateral preoptic/anterior hypothalamic neurons in rats. Brain Res 803:178-188.

Thakkar MM, Portas C, McCarley RW (1996) Chronic low-amplitude electrical stimulation of the laterodorsal tegmental nucleus of freely moving cats increases REM sleep. Brain Res 723:223-227.

Thakkar MM, Strecker RE, McCarley RW (1998) Behavioral state control through differential serotonergic inhibition in the mesopontine cholinergic nuclei: a simultaneous unit recording and microdialysis study. J Neurosci 18:5490-5497.

Torterolo P, Yamuy J, Sampogna S, Morales FR, Chase MH (2001) GABAergic neurons of the laterodorsal and pedunculopontine tegmental nuclei of the cat express c-fos during carbachol-induced active sleep. Brain Res 892:309-319.

Vrontakis ME, Peden LM, Duckworth ML, Friesen HG (1987) Isolation and characterization of a complementary DNA (galanin) clone from estrogen-induced pituitary tumor messenger RNA. J Biol Chem 262:16755-16758

Wang QP, Ochiai H, Nakai Y (1992) GABAergic innervation of serotonergic neurons in the dorsal raphe nucleus of the rat studied by electron microscopy double immunostaining. Brain Res Bull 29:943-948.

Webster HH, Jones B (1988) Neurotoxic lesions of the dorsolateral pontomesencephalic tegmentum-cholinergic cell area in the cat. II. Effects upon sleep-waking states. Brain Res 458:285-302.

Xi M-C, Morales FR, Chase MH (1999) A GABAergic pontine reticular system is involved in the control of wakefulness and sleep. Sleep Res Online 2:43-48.

Yamuy J, Sampogna S, Lopez-Rodriguez F, Luppi PH, Morales FR, Chase MH (1995) Fos and serotonin immunoreactivity in the raphe nuclei of the cat during carbachol-induced active sleep: a doublelabeling study. Neuroscience 67:211-223.

Yamuy J, Sampogna S, Morales FR, Chase MH (1998) c-fos expression in mesopontine noradrenergic and cholinergic neurons of the cat during carbachol-induced active sleep: double-labeling study. Sleep Res Online 1:28-40. 